\title{
Congenital toxoplasmosis in England, Wales, and Northern Ireland: some epidemiological problems
}

\author{
SUSAN M HALL
}

\begin{abstract}
It has been suggested that congenital toxoplasmosis could be prevented by antenatal serological screening, followed by treatment or by termination of pregnancy if infection occurs. The only study of the incidence of congenital toxoplasmosis in England, Wales, and Northern Ireland took place more than 10 years ago. To obtain more recent figures laboratory reports of cases occurring from 1975 to 1980 were analysed. A total of 91 cases were reported over the six years. By criteria established to classify these infections only 34 were congenital, 20 were acquired postnatally, and 37 were unclassifiable. The mean annual number of cases of congenital toxoplasmosis was considerably smaller than that found in other recent studies. The condition could be underdiagnosed or rates of placental transmission could be lower in Britain than in other countries. Variation in reporting criteria of the laboratories made the data difficult to interpret.

Improved diagnosis of congenital toxoplasmosis would not only clarify the epidemiology but would also help clinicians in management of suspected cases. Further antenatal surveys are necessary to assess the role of screening in the prevention of congenital toxoplasmosis.
\end{abstract}

\section{Introduction}

Toxoplasmosis is a common infection caused by the protozoan parasite Toxoplasma gondii. About half of the population in England and Wales acquire specific antibody by the age of 60 years. ${ }^{1}$ Cats and uncooked meat are thought to be the principal sources of human infection, although the exact modes of transmission are not known. When acquired postnatally by immunocompetent individuals toxoplasmosis is usually asymptomatic,

Public Health Laboratory Service Communicable Disease Surveillance Centre, London NW9 5EQ

SUSAN M HALL, MSC, MFCM, senior registrar although it may cause fever and lymphadenopathy. If a pregnant woman acquires toxoplasmosis, the organism may cross the placenta. ${ }^{2}$ Transmission to the fetus occurs in about $45 \%$ of such infections overall, although the rate increases with the length of gestation. ${ }^{3}$ Chorioretinitis, hydrocephalus, and intracranial calcification (the "classic triad") are well recognised signs of congenital toxoplasmosis, although other less specific features such as prematurity, intrauterine growth retardation, hepatosplenomegaly, and jaundice may also occur. ${ }^{4}$ Only 10$20 \%$ of congenitally infected infants, however, have clinically apparent disease at birth. ${ }^{3}{ }^{4}$ Longitudinal studies of asymptomatic infected neonates show that a high proportion of them develop chorioretinitis, moderate to severe neurological sequelae, or both, months or even years later. ${ }^{5}$

There has been much debate in recent British and American publications on the need for antenatal serological screening to detect toxoplasmosis acquired during pregnancy. Congenital toxoplasmosis might then be prevented by treatment or by termination of pregnancy if infection occurs. ${ }^{6} 7$ One of the classic criteria for justifying a screening programme is that the condition to be prevented is an appreciable public health problem. ${ }^{8}$ The only study of the incidence of congenital toxoplasmosis in England, Wales, and Northern Ireland took place more than 10 years ago. ${ }^{9}$ This was a review of laboratory reports to the Public Health Laboratory Service of clinically apparent toxoplasmosis in children aged 6 months to 4 years, and it was decided to repeat this study to estimate the size of the present problem. This would be a relatively cheap, quick, and simple analysis of routinely available data that would not yield information on subclinical cases but, by using published data on the ratio of symptomatic to asymptomatic infections, ${ }^{34}$ would allow estimation of the total incidence of congenital toxoplasmosis.

\section{Methods}

DIAGNOSIS OF TOXOPLASMOSIS IN ENGLAND, WALES, AND NORTHERN IRELAND

The Sabin-Feldman dye test, which is the definitive reference test for toxoplasmosis, and the toxoplasma specific IgM assay are undertaken only at the toxoplasma reference laboratories at the Public 
Health Laboratories in Tooting, Swansea, and Leeds. The toxoplasma specific IgM antibody is a marker of infection acquired during the previous six to eight months. All three laboratories report positive findings (the criteria for which are discussed below) to the Communicable Disease Surveillance Centre. A review of these reports should therefore provide a reasonable estimate of the incidence of clinically apparent congenital toxoplasmosis in England, Wales, and Northern Ireland.

\section{REVIEW OF REPORTS}

The six years from 1975 to 1980 were chosen for review and only children aged 0-4 years were included. No attempt was made to obtain further clinical detail from paediatricians. Information recorded on reports included age and clinical features of the infant (the clinical features were usually transcribed by the laboratory direct from the clinician's remarks on the initial request form); dye test titre, and IgM titre of the infant's serum; and the dye test titre of the mother's serum.

\section{DEFINITIONS OF INFECTION}

Children under 4 years of age may have a positive titre on dye test either because they have congenital toxoplasmosis or toxoplasmosis acquired postnatally or because they are not infected but have acquired antibody transplacentally. This passive antibody has usually disappeared by the age of 6 months, but rarely may persist for up to 2 years. There is no internationally accepted serological or clinical case definition of congenital toxoplasmosis or of toxoplasmosis acquired postnatally presenting at different ages in childhood. Reported cases were therefore assigned to one of three groups based on the following criteria.

Probable congenital infection-Babies under six months were classified as having probable congenital infection if the report form showed either dye test titre $\geqslant 1 / 2000$ with or without specific $\operatorname{IgM}$, plus either two or more clinical features of the "classic triad" or choroiditis or intracranial calcification alone (hydrocephalus alone was not considered sufficiently specific for congenital infection); or specific IgM even if the clinical features were non-specific-for example, small for dates, jaundice, retarded, congenital infection, or dye test titre at least three times that of the maternal titre. The same criteria were used for babies and children 7 months to 4 years but excluding cases with specific IgM after 8 months of age.

Probable postnatally acquired infection-Children were considered to have acquired infection postnatally if the report form showed either positive dye test titre with typical clinical features-for example, pyrexia, lymphadenopathy; or specific IgM in a child over 8 months even without typical clinical features; or rising dye test titre in a child over 1 year.

Unclassifiable-Where clinical features were not specific for congenital or postnatally acquired toxoplasmosis and no IgM or maternal dye test titre was reported, the infection was considered unclassifiable. This group may have included children with congenital or postnatally acquired infection, but there was insufficient clinical and serological information to justify their inclusion in either categories.

\section{Results}

A total of 91 cases were reported over the six years; 45 from Leeds, 25 from Tooting, and 21 from Swansea. The annual number of reports for all patients aged 0-4 years ranged from seven to 20 (table I). Babies under 6 months are shown separately in the table because as a group they would be expected to include the most obvious and severe "classic" congenital cases. The annual totals ranged from 2 to 9 (mean 5.5).

Table II shows that 34 of the 91 cases were classified as probable

TABLE I-No of cases of toxoplasmosis in children aged $0-4$ years reported by laboratories from 1975 to 1980

\begin{tabular}{lrrrrrrr}
\hline Age & 1975 & 1976 & 1977 & 1978 & 1979 & 1980 & Total \\
\hline 56 months & 9 & 8 & 6 & 4 & 2 & 4 & 33 \\
$>6$ months & 9 & 12 & 11 & 10 & 5 & 11 & 58 \\
Total 0-4 years & 18 & 20 & 17 & 14 & 7 & 15 & 91
\end{tabular}

TABLE II-Classification of 91 cases of toxoplasmosis in children aged 0-4 years reported by laboratories from 1975 to 1980 . Figures are numbers of cases

\begin{tabular}{|c|c|c|c|c|}
\hline \multirow{2}{*}{$\begin{array}{l}\text { Classification and } \\
\text { criteria satisfied* }\end{array}$} & \multicolumn{3}{|c|}{ Age (months) } & \multirow{2}{*}{ Total } \\
\hline & $0-6$ & $7-24$ & $25-48$ & \\
\hline $\begin{array}{l}\text { Congenital: } \\
\text { Classic triad plus positive dye test titre } \\
\text { Clinical signs } \text { plus positive dye test titre }_{\text {Specific IgM (clinical signs non-specific) }} \\
\text { High infant to maternal dye test titre } \\
\end{array}$ & $\begin{array}{l}4 \\
4 \\
8 \\
2 \\
\end{array}$ & $\begin{array}{l}9 \\
1 \\
\end{array}$ & 6 & $\begin{array}{r}4 \\
19 \\
8 \\
3 \\
\end{array}$ \\
\hline Total & 18 & 10 & 6 & 34 \\
\hline $\begin{array}{l}\text { Postnatally acquired: } \\
\text { Clinical signs } \ddagger \text { plus positive dye test titre } \\
\text { plus late IgM } \\
\text { Clinical signs plus positive dye test titre } \\
\text { Late IgM (clinical signs non-specific) } \\
\text { Rising titre }\end{array}$ & & $\begin{array}{l}1 \\
5 \\
1\end{array}$ & $\begin{array}{l}3 \\
7 \\
3\end{array}$ & $\begin{array}{r}4 \\
12 \\
3 \\
1\end{array}$ \\
\hline Total & & 7 & 13 & 20 \\
\hline Unclassifiable & 15 & 8 & 14 & 37 \\
\hline Total all cases & 33 & 25 & 33 & 91 \\
\hline
\end{tabular}

* See text for details.

+Choroiditis or intracerebral calcification alone.

$\ddagger$ Pyrexia of undetermined origin and lymphadenopathy, with or without hepatosplenomegaly.

congenital infection and 20 as probably acquired after birth, while 37 were unclassifiable. Over the six years of the review only four infants, all neonates, were reported to have the classic triad of symptoms.

\section{Discussion}

There were two striking findings from this review of laboratory reports of toxoplasmosis in children under 4 years of age. Firstly, the numbers of cases were considerably smaller than other estimates of symptomatic congenital toxoplasmosis in the British Isles published in the past 10 years. One earlier epidemiological study was identical to this one, except that babies under 6 months were excluded and there was no distinction between congenital and postnatally acquired infection. ${ }^{9}$ The results showed that 30-50 cases were reported annually, and these figures have been cited and used in more recent publications to estimate the annual incidence of symptomatic congenital toxoplasmosis in England, Wales, and Ireland-that is, numbers of new cases per 10000 pregnancies per year. ${ }^{1} 1011$

Ruoss and Bourne's study is the only published prospective study of seroconversion in susceptible English women during pregnancy with follow up until delivery. ${ }^{12}$ The authors found a seroconversion rate of three per 1000 susceptible pregnant women. If one quarter of the childbearing population in Britain are already naturally immune, ${ }^{1}$ and the above seroconversion rate is applied to the average annual number of pregnancies during the study period (1975-80), 1730 infections in pregnant women would have been expected each year of the study period. Assuming further that during pregnancy, $45 \%$ of infected women actually transmit the infection to their infants, ${ }^{4}$ about 780 such transmissions would have occurred. Only $10 \%$ to $20 \%$ of congenitally infected infants show symptoms at birth (and are therefore investigated), ${ }^{34}$ so from 80 to 160 cases might have been expected each year of the study period. It should be noted that data from French and American studies were used in the above assumptions about transmission rates and proportions of clinically obvious patients because there was no comparable information about British cases.

A recent study of congenital toxoplasmosis in Scotland showed that the incidence of both symptomatic and asymptomatic infection was at least 0.5 per 1000 live births. ${ }^{13}$ Applying this rate to the annual average of 650000 births for England, Wales, and Northern Ireland from 1975 to 1980, 325 infected babies would have been born each year. Of these, from 30 to 60 would have been clinically obvious at birth using the assumptions described above.

The total numbers recorded during this review were less 
than half those obtained (direct or by using estimates) in previous British studies. The difference is even more striking if only those cases in this study who met the criteria for probable congenital toxoplasmosis (mean 5.7 annually) are included in the comparison. It is notable that over the study period only four neonates were reported to have the classic triad of symptoms.

Several hypotheses may be advanced to explain the differences between the observed and expected incidence of symptomatic CT. The condition may be underdiagnosed; it seems unlikely that paediatricians would not recognise infants with typical infection, but those with no symptoms or with non-specific symptoms might be missed and these may form a larger proportion of British cases than has been observed in other countries.

Alternatively, the rate of placental transmission described in French studies ${ }^{4}$ and used in two of the above estimates of incidence rates may be lower in British mothers. No infected babies were born to the seven "seroconverters" in Ruoss and Bournes's study ${ }^{12}$ although Williams documented three transmissions among 15 seroconverters in his study. ${ }^{13}$ It has been suggested that the initial parasite dose may influence placental transmission and that this may be higher in France than in England because the principal source of the infection there is probably undercooked meat. ${ }^{14}$ The tissue cyst in infected meat may contain several thousand parasites in contrast to the four infective units found in toxoplasma oocysts excreted by cats. Contact with cats may play a larger part in acquisition of toxoplasmosis in Britain than in France. ${ }^{14}$

Thirdly, reporting criteria may be too stringent: the reference laboratories do not report all positive dye test titres to the Communicable Disease Surveillance Centre. Criteria for reporting congenital toxoplasmosis vary slightly. Thus one laboratory selects cases in whom the dye test titre is $\geqslant 1 / 1024$ and there are appropriate clinical symptoms. Preferably there should be specific IgM and a haemaggiutination titre lower than that of the dye test. Another laboratory sets the level for reporting at dye test titre of $\geqslant 1 / 512$ except for those cases where eye symptoms are mentioned; all of such cases with a titre of $\geqslant 1 / 128$ are reported. Furthermore, the decision to report is often a subjective process dependent on several factors: the serological pattern, clinical picture, and age of the child and the serological pattern (if available) and the clinical symptoms of the mother. Some cases not reported by the reference laboratories because of a low dye test titre, negative titre to $\operatorname{IgM}$, or both, may have had congenital toxoplasmosis. The indirect fluorescent antibody IgM assay has not always been reliable in the past $\mathrm{t}^{15}$ and the IgM enzyme linked immunosorbent assay, which is more specific and sensitive, has only recently become available in Britain. ${ }^{16}$

The second principal finding of this study was the problem of studying the epidemiology of congenital toxoplasmosis using routinely reported laboratory data. Difficulties of differentiation between congenital and postnatally acquired toxoplasmosis in infants and young children and insufficient clinical and serological information contributed to the problem. Using these data, it was not possible to determine whether or not congenital toxoplasmosis is an appreciable public health problem in Britain.

There is a need for improved diagnosis of congenital toxoplasmosis. This would not only help to clarify the epidemiology but would also assist clinicians in their management of suspected cases. A satisfactory diagnosis is more likely to be achieved if: (a) clinicians supply the laboratory with full relevant clinical information; $(b)$ repeat serological tests are undertaken (in the infant under 1 year of age, falling dye test titres indicate passively acquired antibody, while in the older child a rising titre indicates postnatally acquired infection); $(c)$ the maternal titres are assayed. There is also a need for further prospective surveys of pregnant women and their babies with detailed follow up of all probable and possible cases. Only then can the effectiveness of treatment, the potential value of vaccination, and the role of antenatal screening be satisfactorily assessed.
I thank Dr Fleck, Dr Kwantes, and Dr Balfour at the toxoplasma reference laboratories and Dr Noah at Communicable Disease Surveillance Centre for their help in preparing this paper and also the laboratory staff, in particular Mr B Chessum, Mr R Payne, and Mr J Bridges.

\section{References}

1 Fleck DG, Kwantes W. The laboratory diagnosis of toxoplasmosis. London: HMSO, 1980. (Public Health Laboratory Service Monograph 13.)

${ }^{2}$ Remington JJ, Desmonts G. Toxoplasmosis. In: Remington JJ, Klein JO, eds. Infectious diseases of the fetus and newborn infant. Philadelphia: WB Saunders, 1976.

${ }^{3}$ Desmonts G, Couvreur J. Congenital toxoplasmosis: a prospective study of the offspring of 542 women who acquired toxoplasmosis during pregnancy. In: Thalhammer $\mathrm{O}$, et al, eds. Perinatal medicine. Sixth European congress, Vienna 1978. Stuttgart, West Germany: George Thieme, 1978.

4 Alford CA, Stagno S, Reynolds DW. Congenital toxoplasmosis: clinical laboratory and therapeutic considerations with special reference to subclinical disease. Bull NY Acad Med 1974; 50:160-81.

5 Wilson CB, Remington JS, Stagno S, Reynolds DW. Development of adverse sequelae in children born with subclinical congenital toxoplasma infection. Paediatrics $1981 ; 66: 767-74$.

6 Anonymous. The epidemiology of toxoplasmosis [Editorial]. Lancet $1981 ; \mathrm{ii}: 1148$.

${ }^{7}$ Wilson CB, Remington JS. What can be done to prevent congenital toxoplasmosis? Am $\mathcal{F}$ Obstet Gynecol 1980;138:357-63.

${ }^{8}$ Wilson JMG, Jungner G. Principles and practice of screening for disease. Public Health Pap 1968;34.

9 Fleck DG. Congenital toxoplasmosis. In: Perinatology. Proceedings of 13th international congress of paediatrics. Vol 1. Vienna: Verlag der Wiener Medizinisden Arcademie, 1971.

10 Anonymous. Toxoplasmosis [Editorial]. $\mathrm{Br} \mathrm{Med} \mathcal{7} 1981 ; \mathbf{2 8 2}: 242-50$.

${ }^{11}$ Fleck DG. The problem of congenital toxoplasmosis. In: Elliott $\mathrm{K}$, Knight $\mathrm{J}$, eds. Intrauterine infections. Amsterdam: Elsevier, North Holland, 1973. (Ciba Foundation symposium 10.)

12 Ruoss CF, Bourne GL. Toxoplasmosis in pregnancy. Fournal of Obstetrics and Gynaecology of the British Commonwealth 1972;79:1115-8.

${ }^{13}$ Williams KAB, Scott JM, MacFarlane DE, Williamson JMW, Elias Jones TF, Williams H. Congenital toxoplasmosis: a prospective survey in the west of Scotland. Fournal of Infection $1981 ; 3: 219-29$.

${ }^{14}$ Broadbent EJ, Ross R, Hurley R. Screening for toxoplasmosis in pregnancy. 7 Clin Pathol $1981 ; 34: 659-64$.

${ }_{15}$ Desmonts G, Naot Y, Remington JS. Immunoglobulin M-immunosorbent agglutination assay for diagnosis of infectious diseases: diagnosis of acute congenital and acquired toxoplasma infections. 7 Clin Microbiol $1981 ; 14: 486-91$

16 Payne RA, Isaac M, Francis JM. An enzyme linked immunosorbent assay (Elisa) using antibody class capture for the detection of anti-toxoplasma IgM. F Clin Pathol 1982;35:892-6.

(Accepted 3 May 1983)

FOR THE HEAD-Let such as love their heads or brains, either forbear such things as are obnoxious to the brain, as Garlick, Leeks, Onions, beware of surfeiting and drunkenness. To purge the Head-The head is purged by Gargarisms, of which Mustard, in my opinion, is excellent, and therefore a spoonful of Mustard put into the mouth, is excellent for one that is troubled with the lethargy: also the head is purged by sneezing; but be sure if you would keep your brain clear, keep your stomach clean. For a rheum in the Head, and the Palsy-Take a red Onion, and bruise it well, and boil it in a little Verjuice, and put thereto a little clarified honey, and a great spoonful of good Mustard, when it is well boiled, raise the sick upright, and let him receive the smell up his nose twice a day, whilst it is very hot. For a rheum in the Head-Boil Pimpernel well in Wine, and drink a draught of the Wine in the evening, hot, but in the morning cold, or Stew Onions in a close pot, and bathe the head and mouth, and nose therewith. For the falling off of the Hair-Beat Linseeds very well, and mix them with Sallad-oil; and when you have well mixed them, anoint the head therewith, and in three or four times using it will help you. To purge the Head-Chew the root of Pellitory of Spain, and chew it on both sides of thy mouth, and as the rheum falls down into thy mouth, spit it out, but retain the root there still, till you think the head is purged enough for that time. (Nicholas Culpeper (1616-54) The Complete Herbal, 1950.) 